CARMEN LLORCA

\title{
En el primer centenario de Lenin
}

Cuando el 22 de enero de 1924 murió Lenin, el general De Bono, jefe de la Pollcfa de Mussolini, le dijo al fundador del fascismo: "Con la muerte de Lenin, tienes un enemigo menos". A lo cual el Duce le respondió: "No, tenemos un inmortal de más».

A un siglo de distancia del nacimiento de Lenin se puede decir que es algo más que un inmortal en el calendario político de su país. Lenin es un mito, un nombre sacralizado y adorado por millones de seres que acuden a venerar su tumba y contemplar, como una reliquia, su cuerpo momificado. Sólo el pueblo ruso es capaz de ofrecer un fenómeno colectivo de esta naturaleza en nuestro siglo. Mientras el Occidente, con el aparato de su lógica, quiere reducir a razonamientos y números todo el misterio de la vida y del pensamiento, el Oriente parece empeñado y obstinado en un nuevo mesianismo político que tiene mucho de religioso. "Si l!egan a borrar a Dios de la tierra-decía Dostoiesvki-, lo encontraremos en el subsuelo". En estas catacumbas de la par sión rusa se está dando forma a un nuevo espiritualismo.

Lo curioso es que tal perseverancia religiosa haya venido a recaer en Lenin. Con independencia de su figura física-que por la expresión soñadora y sonriente de su rostro y la proporción en las medidas medianas de su cuerpo, puede recordar a un icono bizantino-el pensamiento y la acción de Lenin dista mucho del misticismo. Es un revolucionario que juega a ganar. Parecerá esto una incongruencia, pero no es así. La mayor parte de los revolucionarios van a la revuelta por la acción en sí, atraídos por el romanticismo negativo de la destrucción de un orden establecido. Lenin, es cauto, se reserva, se expone to menos posible, dirige la acción desde su gabinete de mando, mueve a los activistas como marionetas, y no está pensando tanto en deshacer lo existente como en adueñarse del poder y utilizarlo en beneficio de su nuevo orden.

Curzio Malaparte en su poco conocida obra "El buen hombre Lenin", definió con mucha claridad las intericiones del revolucionario ruso al decir: "Nunca Lenin peleó por la libertad... sino por el poder, nada más que por el poder. Durante sus años de exilio, desde la primera Iskra hasta su vuelta a Rusia, la palabra "libertad" articula un sonido falso en su boca. Es una de aquellas palabras que pronuncia sonriendo y entornando los ojos. A las hordas de soldados que abandonan las trincheras para volverse sobre Petrogrado, Lenin no promete la libertad, sino la venganza y la paz. A los muilks que hacen retum- 


\section{LLORCA}

bar en las campiñas el canto del gallo rojo, Lenin no promete la libertad, sino la venganza y la tierra. A los obyeros que se aprietan alrededor de los oradores rojos en los patios de las fábricas, Lenin no promete la libertad, sino la venganza y el poder. Las palabras que lanza a los obreros y a los desertores, retumban, rojas y sonoras, de calle en calle, de aldea en aldea, hasta el fon. do de Asias.

\section{"CONSEJOS DE UN AUSENTE"}

En octubre de 1917 escribe Lenin sus "Consejos de un ausente", inspirados en la obra de Marx, "Revoluciór: y contrarrevolución en Alemania». Lenin dice
lo siguiente:

1. No jugar jamás con la insurrección, pero cuando se empiece estar ple. namente convencido de que no hay que detenerse hasta llegar al final.

2. Reunir el lugar y en el momento decisivo, fuerzas muy superiores a las del enemigo, ya que este último, mejor preparado y mejor organizado, destruiria a los insurgentes.

3. Una vez iniciada la insułrección, es preciso actuar con el máximo rigor y pasar, cueste lo que cueste, a la ofensiva. La defensiva es la muerte de la
insurrección.

4. Hay que esforzarse en coger por sorpresa al enemigo y aprovechar el momento en que sus tropas se encuentren dispersas.

$5 .^{\circ}$ Hay que conseguir cada día un éxito, aunque sea poco considerable (se podría decir "cada hora" si se trata sólo de una ciudad) y conservar a cualquier precio la "superioridad moral*.

Quien así escribe no es ciertamente un pensador, podría ser un estratega, un general de Estado Mayor. $Y$ de alguna manera lo es Lenin porcue está mandando sobre unas fuerzas y un partido que ha querido organizar militarmente. Hay que reconocerle el mérito del acierto.

Pero la razón de su triunfo no está solamente en estas caracteristicas que imprime a la revolución. La razón de que ocupe el primer lugar entre los revolucionarios-entre los cuales habia algunos cuyos valores intelectuales sobre. pasaban con mucho los de Lenin-se debe a su obstinación, a su fanatismo, a sus facultades de dirigente, al magnetismo que ejerce sobre las masas, a su despreocupación por las formas y a su indiferencia en materia de sentimentalismos.

Nacido en Simbirsk, en la misma ciudad en que once años más tarde había de ver la luz Kerenski, Lenin hace el recorrido habitual de un revolucionario de su tiempo. Los años de exiliado en occidente le sirven para dos cosas: analizar mejor a su pais, porque lo contempla de lejos, y adueñarse de todo aquello que le resulta más útil del pensamiento alemán. Es muy importante tener presente esta última estimación porque en ella está posiblemente la razón de la actual crisis ideológica del comunismo ruso.

El pensamiento alemán nutre a la revolución rusa, pero una vez que ésta se instala en el poder y se impone la línea ideológica del marxismo-leninismo, este pensamiento se hace sagrado, se persigue toda innovación, y toda evolu- 
ción-maun aquella que está dentro de la misma línea...... tanto por temor a la perdida del poder polítsco como por respeto religioso hacia aquella idea y persona que ha proporcionado el triunfo. De ahí que el pensamiento comunista no se renueve en Rusia, sino fuera de la misma, y surjan nuevos pensadores sobre el sistema ideológico comunista justamente en aquellos jugares que escapan a esta férrea disciplina. $Y$ es otra vez el pensamiento alemán y centro-europeo el que ofrece las bases de una renovación mientras Rusia se hace más y más baluarte de un fanatismo, se hace conservadora en la revolución, alejandose de aquella "revolución permanente" que trataba de imponer Trostky como formula de salvación.

Lukacks, Marcuse. Adam Schaff, Ernst Fischer y algunos otros definidos como los "nuevos galleos" de comunismo, se pelean con Rusia justamente porque revitalizan, examinan y adaptan a los nuevos tiempos le célebre doctrina.

\section{A LOS CIEN ANOS}

A los cien años del nacimiento de Lenin, se puede decir que su vida constituyó un auténtico éxito y que estuvo marcada por el destino más singular. Pero cincuenta años de revolución en su pais pueden ser objeto de otras consideraciones. Isaac Deustcher la ha definido como la "revolución incompleta». En el centenario de Lenin, Pefer Weiss estrena en Berlín una obra sobre Trostky, el gran perdedor. En el centenario de Lenin, la casa donde vivió mucho tiempo en Zurich, y desde donde salló para ocupar un tren precintado que habia de conducirle a su país, es destruida para levantar sobre el solar un nuevo edificio. En la misma Rusia no saben bien cómo enfocar una conmemoración que tiene mucho de religiosa, porque como dice Louis Pischer: Lenin vive. Los dirigentes soviéticos "se aconsejaron de Lenin". Esta actitud se halla exacta" mente en el borde mismo de la deificación y la resurrección. Una jefatura carente de confianza e ideas nuevas, se apoya en las palabras y los hechos de Lenin. Resulta simbólico que las multitudes apinadas vean a sus dirigentes, el 7 de noviembre, el 1 de mayo y en ocasiones especiales, encima del mausoleo de Lenin. Se sostienen sobre él. Dentro de la tumba piramidal, hecha de brillante granito rojinegro traídu de Vinnitza (Ucrania), reposa el cadáver que parece vivo. El Kremlin es muy susceptible a las calumnias contra la hazaña química que representó el embalsamamiento de Lenin. En los años treinta, algunos periódicos extranjeros afirmaron que la pálida momia era una figura de cera. Ante ello, un grupo do extranjeros, del que formé parte, fue invitado a descender a las profundidades del santuario, donde el profesor Boris 1 . Zbarski, químico embalsamador, hizo alusión al proceso secreto mediante el cual pudo lograrse la momificación, y calculó que el cadáver podría durar un siglo. Luego abrió la caja de cristal, herméticamente cerrada, que contiene la reliquia, pellizcó la nariz de Lenin y le hizo volver la cabeza hacia la derecha y hacia la izquierda. No era de cera. Era Lenin. Ese iconoclasta es actualmente un icono ruso moderno, y millones de personas hacen cola y contemplan, admiradas, el milagro de su conservación en la carne.

"Lenin vive", pero su revolución ha cambiado incluso antes de producirse en aquellos paises que él consideraba como piezas fundamentales para el sostenimiento de la revolución en su patria. Ni Alemania, ni Centro Europa se sumaron al acontecimiento. Tan inseguro estaba Lenin de que su inicial triunfo se consolidase, que a los tres meses de ocupar el poder proclamaba 


\section{LLORCA}

como un gran éxito el hecho de que hubiese durado más que la comuna de Paris. Con ello se daba por satisfecho, porque la aventura de aquella prueba le producía el vértigo de un salto en el abismo de la Historia.

Hubo, sin embargo, algún estallido. En 1919, Alemania vivió la revuelta de los espartaquistas, Hungría al experimento de Bela Kun, Baviera el gobierno de Kurt Eisner, Italia las huelgas y los atentados anarquistas, se derrumbaron los Imperios Centrales, cayó la monarquía otomana, mientras en Rusia la llI In. ternacional lanzaba el segundo manifiesto del partido comunista.

Pero mientras no existe en la revolución rusa un movimiento que se parezca a la reacción thermidoriana de la revolución francesa, en Europa nace inmediatamente una repulsa frente a la gran amenaza que viene de Rusia. En Alemania, Rosa Luxemburgo y Liebknecht son eliminados; Bela Kun es derrotado y desaparece para no volverse a saber nada de él. En Italia, en ese mismo año crucial de 1919. Mussolini funda el partido fascista y Don Luigi Sturzo crea el partido popular católico. Europa occidental busca sus propias fórmulas de saln vación y se acentúa esa barrera que siempre ha existido y cuyas fronteras terminan ante aquellas tierras que durante siglos han estado ocupadas por los turcos y que tienen un concepto de la libertad bien diferente al del Occidente europeo.

A medio siglo de distancia de aquellos hechos, se observa que la táctica de penetración comunista en Occidente ha cambiado, mientras, haciendo uso de la revolución, se ha extendido por el Oriente, por Asia. Si se contempla el mapa del mundo, se puede apreciar la gran extensión de territorios que han sido sometidos a este experimento. Todo se ha hecho en nombre de Lenin que, gracias a haber ocupado tan poco tiempo el poder, ha podido pasar a la leyenda sin haber sufrido la crítica de sus fracasos económicos. Stalin, que ha sido el gran artífice de este nuevo imperio, ya ha sido juzgado, aunque, sin duda, volverá a ocupar mejor posición en el recuerdo de sus compatriotas.

En nombre de Lenin actúan Mao-Tse-Tung, Ho-Chi-Min y cuantos nuevos jefes de revoluciones nacionales aparecen en el horizonte político. Todos parecen querer estar vinculados y sometidos a la protección de este profeta, como fórmula de seguridad ante el nuevo fetichismo. Sólo parece escapar a este hieratismo doctrinario el movimiento revolucionario de la América Central y del Sur. Pese a las vinculaciones económicas y políticas que pueda tener con Rusia, su revolución aparece con unos perfiles propios. La presencia e influencia de Trostky en México puede muy bien haber influido en ello.

En cualquier caso digamos que la vida de Lenin ha sido bien aprovechada por sí mismo y sus seguidores. Ha sido el padre de todas las revoluciones de nuestro siglo, aun sin haber participado en ninguna de ellas, porque hasta en el asalto al poder ruso en octubre de 1917 el verdadero luchador y árbitro de la situación que puso en manos de Lenin el poder fue Trostky. 